\title{
Obesity in Children with Leptin Receptor Gene Polymorphisms
}

\author{
Aleksandr Abaturov ${ }^{1}$, Anna Nikulina ${ }^{1, *}$
}

\begin{abstract}
Introduction: The study of single nucleotide polymorphisms (SNPS) of the leptin receptor gene (LEPR) based on next generation genomic sequencing (NGS) data is becoming an increasingly important aspect of diagnosis, treatment and prevention of both metabolically healthy (MHO) and metabolically unhealthy obesity (MUO) phenotypes.

Material and methods: 35 obese children 6-18 years old were examined by the NGS method with bioinformatic analysis. The main group $(n=18)$ was formed by children with MUO, according to the recommendations of the expert group of the National Heart, Lung, and Blood Institute. The control group $(n=17)$ was represented by children with MHO. Statistical methods were used: analysis of variance, Wald's sequential analysis, Spearman's correlation analysis, analysis of nominal data and multiple discriminant analysis. Results: 10 types of non-synonymous SNPs (rs3790435, rs1137100, rs2186248, rs70940803, rs79639154, rs1359482195, rs1137101, rs1805094, rs13306520, rs13306522) of the LEPR gene in obese children have been identified. Multiple discriminant analysis demonstrated that the following LEPR SNPs are of greatest importance in the development of MUO: rs3790435, rs 13306522, rs13306520. Analysis of nominal data revealed significant differences in the groups for Copy number variation (CNV) rs 3790435 of the LEPR gene. Wald's analysis allowed us to identify 6 important predictors of MUO ( $I \geq 0.5)$ : 2 CNV rs3790435 (Relative Risk, RR $=2$, Prognostic coefficient, $P C=+2.76$ ); male gender of the child $(\mathrm{RR}=1.3, \mathrm{PC}=+1.35)$; $\mathrm{rs} 3790435(\mathrm{RR}=1.9, \mathrm{PC}=+2.76)$; hyperleptinemia more than $40.56 \mathrm{ng} / \mathrm{ml}(\mathrm{RR}=2, \mathrm{PC}=+3)$; CNV rs1359482195 $\geq 3(R R=1.9, P C=+5.8) ;$ SNP of the LEPR gene $\geq 4(R R=3.8, P C=+5.8)$.

Conclusion: Children with the genotype rs 3790435 gene LEPR had signs of MUO more often.
\end{abstract}

\section{KEYWORDS}

obesity phenotypes; children; leptin receptor gene; single nucleotide polymorphisms; next generation genomic sequencing

\section{AUTHOR AFFILIATIONS}

${ }^{1}$ Dnipro State Medical University (DSMU), Dnipro, Ukraine

* Corresponding author: Dnipro State Medical University (DSMU), Street 9, V. Vernadskogo, 49044, Dnipro, Ukraine; e-mail: anna.nikulina.201381@gmail.com

Received: 11 November 2020

Accepted: 13 September 2021

Published online: 11 November 2021

Acta Medica (Hradec Králové) 2021; 64(3): 158-164

https://doi.org/10.14712/18059694.2021.27

(c) 2021 The Authors. This is an open-access article distributed under the terms of the Creative Commons Attribution License (http://creativecommons.org/licenses/by/4.0), which permits unrestricted use, distribution, and reproduction in any medium, provided the original author and source are credited. 


\section{INTRODUCTION}

The key role in the regulation of the body's energy metabolism is played by leptin (LEP) produced by adipocytes, which activates the leptin receptor (LEPR) of hypothalamic neurons $(1,2)$. Activation of the leptin receptor leads to increased transcription of anorexigenic pro-opiomelanocortin (POMC) and inhibition of the transcription of orexigenic neuropeptides agouti-related protein (AgRP) and neuropeptide Y (NPY) (3). Polymorphisms of the LEPR gene, which is located on chromosome 1 (1p31.3), associated with the development of obesity, are inherited in an autosomal recessive manner. Biallelic nonsynonymous polymorphisms of the LEPR gene located in exons can lead to dysfunction of the LEP/LEPR system by altering the structure of the leptin receptor protein. LEPR anomalies may be accompanied by the disturbance interaction of the receptor with LEP, the lack of LEPR excitation, the appearance of solute forms of LEPR that are not able to fix on the cell membrane, and the disturbance of interaction of the LEPR intradomain with components of intracellular signal conductivity cascades. The absence of the LEPR signal leads to the development of obesity, hyperphagia, and deficiency in the production of pituitary hormones already in the early period of childhood $(4,5)$. The prevalence of pathogenic LEPR mutations in a cohort of patients with severe monogenic early-onset obesity is $1.9 \%$ (6). There are currently 38 documented mutations in the LEPR gene associated with obesity. Most of the mutations are located in the region that encodes the extracellular domain, especially the leptin-binding site or activation domain of the receptor molecule (7). Missense mutations R612H, A409E, W664R, and H684P cause complete loss of leptin signaling, hyperphagia, severe obesity with early clinical manifestation, impairment of immune function and delay of puberty (8).

The detection of variants of leptin receptor gene polymorphisms based on next generation genomic sequencing (NGS) data is becoming an increasingly important aspect of diagnosis, treatment and prevention of both metabolically healthy (MHO) and metabolically unhealthy (MUO) obesity phenotypes associated with the formation of insulin resistance $(9,10)$. However, till now most studies have not examined the genetic effects of gene copies, including LEPR.

Objective: to determine the contribution of various SNPs of the LEPR gene and the CNV of gene regions to the development of metabolically unhealthy obesity and their importance in the diagnosis of various phenotypes of obesity in children.

\section{MATERIAL AND METHODS}

To accomplish the assigned tasks, a clinical and genetic examination was carried out in 35 children $6-18$ years old with obesity, according to the recommendations of The American College of Medical Genetics and Genomics (ACMG) (11). The study was conducted among a Caucasian cohort of children with polygenic obesity.

Criteria for inclusion: all children enrolled in the study had a BMI greater than the 95th percentile or 2 SDS and underwent inpatient treatment in the endocrinology department.

Exclusion criteria: patients with hereditary syndromes accompanied by obesity and diseases, the treatment of which requires the use of drugs that affect the metabolism of carbohydrates and lipids; pregnant.

The main group included of 18 children with metabolically unhealthy obesity (MUO), according to the recommendations of the expert group of the National Heart, Lung, and Blood Institute, USA - NHLBI (12). The control group was formed of 17 children with metabolically healthy obesity (MHO). For inclusion in the main observation group, the presence of abdominal obesity and two of the presented criteria were taken into account: 1). Fasting glycemia $\geq 5.6 \mathrm{mmol} / \mathrm{L}(13) ; 2)$. High-density lipoprotein (HDL) $\leq 1.03 \mathrm{mmol} / \mathrm{L}$ or less than 10th percentile of the age norm; 3 ). Triacylglyceride (TAG) $\geq 1.7 \mathrm{mmol} / \mathrm{L}$ or more than the 90th percentile of the age norm; 4) Systolic blood pressure (SBP) above the 90th percentile for a given age, gender and height (12). The abdominal type of obesity was determined according to the consensus of the International Diabetes Federation (IDF), based on the excess of the waist circumference over the 90th percentile for children 6-15 years old or more than $94 \mathrm{~cm}$ for boys aged 16-18 years and more than $80 \mathrm{~cm}$ for girls $16-18$ years old (14-16).

Laboratory examination for the formation of observation groups for obesity phenotypes included general clinical methods. Blood samples were obtained after an overnight fast by venipuncture in vacutainer gel tubes, and serum was separated from cells by centrifugation in a certified laboratory "Synevo" (Dnipro, Ukraine) using an analyzer and Cobas 6000 test system; Roche Diagnostics (Switzerland). The analysis of serum glucose was carried out by the hexokinase method; the determination of triglycerides and high-density lipoproteins of blood plasma was carried out by the enzymatic - colorimetric method. $\mathrm{HbAlc}$ was analyzed using the immunoturbidimetric method, certified according to the National Glycohemoglobin Standardization Program (NGSP) and standardized according to the reference values adopted in the Diabetes Control and Complications Trial (DCCT). The level of HbAlc 4.8-5.9\% of total hemoglobin in venous blood was considered normal. Insulin was analyzed using the electrochemiluminescence immunoassay method (ECLIA). The level of basal insulin in venous blood of 2.6-24.9 $\mu \mathrm{IU} / \mathrm{ml}$ was considered normal. Insulin resistance was estimated using the Homeostasis Model Assessment for Insulin Resistance (HOMA-IR): Insulin $(\mu \mathrm{IU} / \mathrm{ml}) \times$ Fasting blood glucose $(\mathrm{mmol} / \mathrm{L}) / 22.5$. An increase in insulin resistance was observed at HOMA-IR > 95th percentile according to the percentile curves recommended by the IDEFICS Consortium for the European population according to the age and sex of the child $(17,18)$.

Determination of serum leptin level was performed using radioimmunoassay using an analyzer and LDN test system (Germany), reference values for girls were 3.7$11.1 \mathrm{ng} / \mathrm{ml}$, for boys $2.0-5.6 \mathrm{ng} / \mathrm{ml}$.

Height $(\mathrm{cm})$ was measured using Heightronic Digital Stadiometer ${ }^{\circledR}$ to the nearest $0.1 \mathrm{~cm}$. Weight $(\mathrm{kg})$ and body fat percentage was measured using Tefal Bodysignal body 
composition analyzer (France). The calculation of the percentage of fat or body fat (BF) in the body was performed automatically with a discreteness of $0.1 \%$, according to the requirements of Tefal Bodysignal, with the evaluation of results according to the unified centile scales for children of this age $(19,20)$. Waist circumference (WC), hip circumference (HC) was measured using a standardized anthropometric tape, measuring the circumference at the midpoint between the top of the iliac crest and the lower part of the lateral rib cage to the nearest $0.1 \mathrm{~cm}$. BMI was converted to SDS by means of the current WHO growth references (21).

Systolic and diastolic blood pressure (SBP and DBP) were measured using a digital oscillimetric device, Dinamap ProCare (GE Healthcare).

Molecular genetic testing included complete genomic NGS with venous blood sampling in a certified CeXGat laboratory (Tubingen, Germany) using the Illumina CSPro ${ }^{\circledR}$ Certified service provider platform. Average amount of DNA ( $\mu \mathrm{g})$ in samples - 0.875. Library Preparation: Quantity used 50 ng. Library Preparation Kit: Twist Human Core Exome plus Kit (Twist Bioscience). Sequencing parameters: NovaSeq 6000; $2 \times 100 \mathrm{bp}$. QC values of sequencing, Q30 value: $96.07 \%$.

Bioinformatic analysis - demultiplexing of the sequencing reads was performed with Illumina bcl2fastq (version 2.20). Adapters were trimmed with Skewer, version 0.2.2 (22). DNA-Seq: Trimmed raw reads were aligned to the human reference genome (hg19-cegat) using the Burrows-Wheeler Aligner, BWA - mem version 0.7.17-cegat (23). ABRA, version 2.18 (24) was used for local restructuring of readings in target regions to improve more accurate detection of indels in the genome during mutagenesis. Proprietary readout tools, alignment with more than one locus with the same alignment score, were used; duplicate reads were discarded.

Variant calling: additional proprietary software was used to detect variants of polymorphisms, including variants with low frequencies (Observed frequency of the alternative allele in the range, OFA up to $2 \%$ of sequenced readings). The mutation variants were annotated based on various publicly available databases (Ensembl v100, RefSeq Curated (20200723), CCDS r22, dbSNP154, GnomAD 2.1 (exonic) and 3.0 (genomic), Gencode 34). Copy number variations (CNV) were found by comparing the number of reads that overlap the target genome regions ("coverage") with the expected number in the cohort of reference samples. All synonymous SNP types were excluded from the study.

The quality of FASTQ files was analyzed using FastQC, version 0.11 .5 -cegat (25). The plots were created with ggplot2 (26) in $\mathrm{R}$ version 3.6.1 (27). When interpreting the data of bioinformatic analysis, the combined annotated dependent depletion (CADD) was calculated for each identified non-synonymous SNP of the LEPR gene $(28,29)$ and the software products FILTUS (30), SeqVISTA (31), Mutationassessor (32) were used.

Statistical processing of the results using parametric, nonparametric methods included: analysis of variance with the calculation of the Student's test $(\mathrm{t})$; sequential Wald analysis with the calculation of the relative risk
(Relative Risk - RR) and the prognostic coefficient (PC); Spearman correlation analysis with calculation of Spearman's rank correlation coefficient $(\rho)$, analysis of nominal data with calculation of Chi-square test $\left(\chi^{2}\right), \chi^{2}$ test with Yates correction, $\chi 2$ test with correction for likelihood, Fisher's exact test (p), Cramer test (V), Pearson's contingency coefficient (C), normalized value of Pearson's coefficient $\left(C^{\prime}\right)$; multiple discriminant analysis with the calculation of the coefficients of the standardized canonical discriminant function ( $C_{i}$ MUO). The critical value of the level of statistical significance (p) for all types of analysis was taken at the level of $\mathrm{p}<0.05(5 \%)$. To reduce the sensitivity of computational procedures to the size of the sample presented, we used special methods that reduce the magnitude of computation errors by multivariate statistical processing of biometric data to obtain verified confidence coefficients (33). Statistical processing of the results was performed using Microsoft Excel (Office Home Business 2KB4Y-6H9DB-BM47K-749PVPG3KT) and STATISTICA 6.1 software (StatSoftInc, no. AGAR909E415822FA).

\section{RESULTS}

The age distribution of polygenic obesity patients who took part in the survey was characterized by the following features. The proportion of children 6-10 years old (pre-pubertal period), in the main group, was $5.6 \%(1 / 18)$, $11-14$ years old (early pubertal period) - 50\% (9/18), 15-18 years old (late puberty period) - $44.4 \%(8 / 18)$. The proportion of children 6-10 years old in the control group was $5.8 \%$ (1/17), $11-14$ years old $-47.1 \%$ (8/17), $15-18$ years old $47.1 \%(8 / 17), p>0.5$. The proportion of adolescents in the main group was $94.4 \%$ (17/18), in the control group - $94.2 \%$ $(16 / 17), p>0.5$. The average age of patients in the observation groups was $12.06 \pm 1.25$ years. The proportion of boys in the main group was $61.1 \pm 5.5 \%$ (11/18), while in the control group the proportion of boys in the study population was $47.06 \pm 4.1 \%$ (8/17), $\mathrm{p}=0.049$.

Anthropometric examination revealed that in children with different phenotypes of obesity in the percentage of BMI, taking into account the age and sex of the child, no statistically significant difference in the comparison groups was observed. The absence of statistically significant differences in the frequency of obesity $(p>0.05)$ is due to the approach to the formation of survey groups, Table 1.

In order to take a part of children from BMI, but to surpass the 100th percentile in case of young variants of obesity phenotypes, and to the classification of extreme obesity in children, proponed by the American Heart Association and the Obesity Society (34). The MUO phenotype was detected in $64.5 \pm 7.3 \%$ of children, the MHO phenotype - in $35.5 \pm 6.9 \%$ of children with extreme obesity. The share of children with extreme obesity of class III (with body weight more than $140 \%$ of the 95 th percentile) in those surveyed with the MUO phenotype was $25 \pm 6.5 \%$, while among those surveyed with the MHO phenotype $7.3 \pm 4.1 \%$. Thus, children with the MUO phenotype have a higher genetic predisposition to develop severe obesity. 
Tab. 1 Average values of anthropometric and manometric examination of children with different phenotypes of obesity.

\begin{tabular}{|c|c|c|c|}
\hline Indicator & $\begin{array}{l}\text { Children } \\
\text { with MUO } \\
(\mathrm{M} \pm \mathrm{m})\end{array}$ & $\begin{array}{l}\text { Children } \\
\text { with } M H O \\
(M \pm m)\end{array}$ & $\begin{array}{c}\text { Probability, } \\
\text { p }\end{array}$ \\
\hline BMI in percentiles, $\%$ & $98.8 \pm 0.34$ & $98.0 \pm 0.4$ & $p>0.05$ \\
\hline $\begin{array}{l}\text { Proportion of children } \\
\text { with extreme obesity } \\
\text { of the III class } \\
\text { (with body weight } \\
\text { more than } 140 \% \\
\text { from } 95 \text { percentile), \% }\end{array}$ & $26 \pm 6.5$ & $7.3 \pm 4.1$ & $p<0.05$ \\
\hline $\begin{array}{l}\text { Physical development } \\
\text { in percentiles }\end{array}$ & $68.8 \pm 4.7$ & $74.3 \pm 6.5$ & $p>0.05$ \\
\hline BF in girls, $\%$ & $38.2 \pm 2.3$ & $28.9 \pm 0.8$ & $p<0.05$ \\
\hline BF in boys, $\%$ & $35.5 \pm 2.5$ & $25.0 \pm 2.1$ & $p<0.05$ \\
\hline WC in girls, $\mathrm{cm}$ & $92.6 \pm 4.2$ & $74.5 \pm 3.1$ & $p<0.05$ \\
\hline WC in boys, $\mathrm{cm}$ & $111.6 \pm 3.2$ & $91.7 \pm 4.8$ & $p<0.05$ \\
\hline $\begin{array}{l}\text { Correlation WC/HC } \\
\text { in girls }\end{array}$ & $0.92 \pm 0.04$ & $0.74 \pm 0.1$ & $p<0.05$ \\
\hline $\begin{array}{l}\text { Correlation WC/HC } \\
\text { in boys }\end{array}$ & $0.98 \pm 0.04$ & $0.84 \pm 0.02$ & $p<0.05$ \\
\hline $\begin{array}{l}\text { Proportion of children } \\
\text { with SBP exceeding } \\
\text { the } 95 \text { th percentile, } \%\end{array}$ & $27.3 \pm 6,7$ & $9.8 \pm 4,6$ & $p<0.05$ \\
\hline
\end{tabular}

Mean WC levels and WC/HC ratios in both boys and girls had statistically significant differences $(p<0.05)$ in the comparison groups. In boys and girls with MUO phenotype, the average level of WC was $111.63 \pm 3.21$ and $92.55 \pm$ $4.18 \mathrm{~cm}$, respectively, the ratio of $\mathrm{WC} / \mathrm{HC}$ was $0.98 \pm 0.04$ and $0.91 \pm 0.04$, respectively, associated with abdominal obesity according to IDF Consensus 2007 (35).

The proportion of children in the comparison subgroups who had a SBP higher than the 95th percentile, which is associated with hypertension among children with the MUO phenotype was almost three times higher than among children with the MHO phenotype, namely -
$27.3 \pm 6.3 \%$ and $9.8 \pm 4.6 \%, p<0.05$. As a result of laboratory examination of carbohydrate metabolism in children with different phenotypes of obesity, the following results were obtained, Table 2.

Tab. 2 Features of carbohydrate and fat metabolism in children with different obesity phenotypes.

\begin{tabular}{|l|c|c|c|}
\hline Indicator & $\begin{array}{c}\text { Children } \\
\text { with } \mathbf{M U O} \\
(\mathbf{M} \pm \mathbf{m})\end{array}$ & $\begin{array}{c}\text { Children } \\
\mathbf{w i t h} \mathbf{M H O} \\
\mathbf{( M \pm \mathbf { m } )}\end{array}$ & $\begin{array}{c}\text { Probability, } \\
\mathbf{p}\end{array}$ \\
\hline $\begin{array}{l}\text { Fasting blood glucose, } \\
\text { mmol/L }\end{array}$ & $4.9 \pm 0.1$ & $3.9 \pm 0.2$ & $\mathrm{p}<0.05$ \\
\hline HbA1c, \% & $5.7 \pm 0.1$ & $4.9 \pm 0.1$ & $\mathrm{p}<0.05$ \\
\hline HOMA-IR & $6.2 \pm 1.6$ & $3.6 \pm 0.4$ & $\mathrm{p}<0.05$ \\
\hline $\begin{array}{l}\text { Proportion of children } \\
\text { with HOMA-IR } \\
\text { exceeding the } 95 \mathrm{th} \\
\text { percentile, \% }\end{array}$ & $88.2 \pm 0.1$ & $36.4 \pm 0.4$ & $\mathrm{p}<0.05$ \\
\hline Leptin in boys, ng/mL & $39.3 \pm 8.9$ & $26.0 \pm 6.4$ & $\mathrm{p}<0.05$ \\
\hline Leptin in girls, ng/ml & $47.8 \pm 4.4$ & $32.5 \pm 4.3$ & $p<0.05$ \\
\hline
\end{tabular}

As a result of NGS, 10 types of nonsynonymous SNPs (rs3790435, rs1137100, rs2186248, rs70940803, rs79639154, rs1359482195, rs1137101, rs1805094, rs13306520, rs13306522) of the LEPR gene cohort were identified in 35 children.

Multiple discriminant analysis with the calculation of the coefficients of the standardized canonical discriminant function showed differences in the studied groups and the contribution of each of the 10 types of detected LEPR SNPs to the formation of MUO, Table 3.

The presented results of multiple discriminant analysis of 10 types of non-synonymous SNPs of the LEPR gene demonstrate that rs3790435, rs13306522, rs13306520, rs70940803, rs2186248, rs1359482195 make a certain contribution to the formation of MUO in children.

Analysis of nominal data on the criteria for assessing the significance of differences in outcomes depending

Tab. 3 Characteristics of SNP types of the LEPR gene and their contribution to the formation of metabolically unhealthy obesity.

\begin{tabular}{|l|c|c|c|c|c|c|}
\hline dbSNP & Ref & Alt & Consequence & Codon Change & CADD & C MUO \\
\hline rs3790435 & T & C & 5_prime_UTR & $-/-$ & 17.34 & 0.939 \\
\hline rs1137100 (exon-2) (K109R) & A & G & missense & aAgaca/aGgaca & 17.74 & -0.389 \\
\hline rs2186248 & G & T & intronic & $-/-$ & 5.441 & 0.862 \\
\hline rs70940803 & T & G & intronic & $-/-$ & 1.642 & -0.894 \\
\hline rs79639154 & T & G & intronic & $-/-$ & 2.884 & - \\
\hline rs1359482195 & C & A & splice_region & $-/-$ & 21.70 & -0.344 \\
\hline rs1137101 (exon-4) (Q223R) & A & G & missense & cAgtca/cGgtca & 18.44 & 0.002 \\
\hline rs1805094 (exon 14) (K656N) & G & C & missense & aaGgag/aaCgag & 9.128 & - \\
\hline rs13306520 & A & G & intronic & $-/-$ & 4.568 & -0.870 \\
\hline rs13306522 & G & A & intronic & $-/-$ & 0.326 & 0.914 \\
\hline
\end{tabular}

Comment: dbSNP - database identifier ("rs" number) of this variant in dbSNP. Ref - reference allele. Alt - alternative allele. Consequence functional consequence of the variation in relation to the transcript. The nucleotide change and position relative to the coding sequence of the affected transcript in HGVS nomenclature: c. CDS Position Reference Base > Alternative Base. Example: c.223A>T. Codon Change - the affected base is written as a capital letter in both codons. Example: aAt/aCt. This column is empty if the variant is intergenic. CADD - Combined Annotation Dependent Depletion $(19,20)$. C MUO - coefficients of the standardized canonical discriminant function. 
on the impact of a risk factor demonstrated significant differences in the observation groups in the CNV of the LEPR gene with rs3790435: Pearson Chi-Square $\left(\chi^{2}\right)=$ 6.59, $\mathrm{p}=0.01 ; \chi 2$, Continuity Correction $=6.98, \mathrm{p}=0.009$; Yates's correction $\chi 2$ (Likelihood Ratio) $=4.84, \mathrm{p}=0.03$; Fisher's Exact Test $(\mathrm{p})=0.013, \mathrm{p}<0.05$, with a minimum value of the expected phenomenon of 5.5. The assessment of the strength of the relationship between the risk factor and the outcome depending on the CNV of the LEPR gene c rs3790435 was relatively strong: Cramer's test $(V)=0.44$, Pearson's contingency coefficient $(C)=0.4$, normalized Pearson's coefficient $\left(C^{\prime}\right)=0.57, \mathrm{p}<0.05$ (Table 4).

Analysis of the prognostic load of factors involved in the development of MUO, according to Wald's sequential analysis, allowed them to be distributed in descending order as follows ( $\mathrm{I} \geq 0.5)$ : $2 \mathrm{CNV}$ rs3790435 $(\mathrm{RR}=2, \mathrm{PC}=+2.76)$; male gender of the child $(\mathrm{RR}=1.3, \mathrm{PC}=$ $+1.35)$; $r s 3790435(\mathrm{RR}=1.9, \mathrm{PC}=+2.76)$; hyperleptinemia more than $40.56 \mathrm{ng} / \mathrm{ml}(\mathrm{RR}=2, \mathrm{PC}=+3)$; 3 or more $\mathrm{CNV}$ rs1359482195 ( $R R=1.9, P C=+5.8)$; more than 4 SNPs of the LEPR gene in an individual ( $R R=3.8, P C=+5.8)$.

The presence of the rs70940803 polymorphism was associated with hyperleptinemia in both children with MHO $(\rho=+0.3)$ and MUO $(\rho=+0.4), p<0.05$. At the same time, the rs1137101 polymorphism in children with MHO had an inverse correlation with hyperleptinemia $(\rho=$ $-0.62), p<0.05$.

\section{DISCUSSION}

In this work, we demonstrated the role of CNV of genes of different genotypes of single nucleotide polymorphisms of the LEPR gene in the formation of polygenic obesity and proved their association with the possibility of the formation of certain phenotypes of MUO and MHO among the Caucasian population. Insulin resistance is the main criterion that distinguishes MUO from MHO. The HOMA-IR index exceeding the 95th percentile was recorded 2.4 times more often among patients with MUO compared with chil- dren with MHO, which was confirmed in a large number of previous studies that studied the effect of exposome on metabolic-associated diseases (10-17).

In our study, predictors of MUO were hyperleptinemia and male sex. A cross-sectional study by L. H. Barstad et al. (36) among Norwegian adolescents 12-18 years old seeking treatment for morbid obesity also showed similar gender differences. Namely, MUO signs were more often observed in boys (in 29\% of cases) according to the following criteria: an increase in the level of triacylglycerides, systolic blood pressure, a decrease in the level of high-density lipoproteins compared with girls, in $19 \%$ of cases (17).

Our data are confirmed by the results of modern studies, which found that insulin resistance is associated with dysfunction of the LEP/LEPR system. Analysis of the scientometric PubMed database showed that the most studied association of obesity and type 2 diabetes with the following LEPR SNPs: rs3790435 and missense mutations rs1137100, rs1137101, rs1805094. The rs1137100 polymorphism is characterized by the replacement of Lys109Arg in the cytokine homology (CK) domain, rs1137101 - Gln223Arg in the loop of the CK-domain, rs1805094 - Lys656Asn in the domain of fibronectin type III of the LEPR molecule. It was shown that monogenic obesity is caused by homozygous mutations rs1137100, rs1137101, rs1805094, which are located in gene regions encoding functionally significant domains of the LEPR protein (38).

At the same time, there are conflicting data on the significance of mutations in the exons of the LEPR gene in the development of polygenic obesity. Thus, Aline Dos Santos Rocha et al. (39) demonstrated an association between $\mathrm{rs} 1137100(\mathrm{G})(\mathrm{OR}=1.92 ; 95 \% \mathrm{CI}=1.18-3.14)$ and overweight / obesity in children. Takuro Furusawa et al. (40) found no significant difference in the observation groups for this polymorphism. Ehab M.M. Ali (41) demonstrated that allelic frequencies of LEPR rs1137101 (Q223R) were significantly higher in obese subjects compared with non-obese ones in without obesity controls. At the same time, Malgorzata Roszkowska-Gancarz et al. (42) did not

Tab. 4 Genotypes and Copy number variation of the LEPR gene in individuals with MHO and MUO.

\begin{tabular}{|c|c|c|c|c|c|c|c|c|c|c|c|c|}
\hline \multirow{3}{*}{$\begin{array}{l}\text { SNP (genotypes: HOMP/ } \\
\text { HET/HOMN) }\end{array}$} & \multicolumn{6}{|c|}{ Genotype (\%) } & \multicolumn{6}{|c|}{$\operatorname{CNV}(\%)$} \\
\hline & \multicolumn{3}{|c|}{ MHO } & \multicolumn{3}{|c|}{ MUO } & \multicolumn{3}{|c|}{ MHO } & \multicolumn{3}{|c|}{ MUO } \\
\hline & HOM $^{p}$ & HET & HOMN $^{N}$ & $\mathrm{HOM}^{\mathrm{p}}$ & HET & HOMN $^{N}$ & 1 & 2 & $\geq 3$ & 1 & 2 & $\geq 3$ \\
\hline rs3790435 (TT/TC/CC) & 5.9 & 41.2 & 52.9 & 0 & 83.3 & 16.7 & 58.9 & 41.1 & 0 & 16.7 & 83.3 & 0 \\
\hline rs1137100 (AA/AG/GG) & 0 & 52.9 & 47.1 & 0 & 50.0 & 50.0 & 47.1 & 52.9 & 0 & 50.0 & 44.4 & 5.6 \\
\hline rs2186248 (TT/TC/CC) & 5.9 & 5.9 & 88.2 & 0 & 0 & 100.0 & 5.9 & 0 & 94.1 & 0 & 0 & 100.0 \\
\hline rs70940803 (GG/TG/TT) & 0 & 17.6 & 82.4 & 0 & 13.5 & 86.5 & 82.4 & 0 & 17.6 & 76.5 & 23.5 & 0 \\
\hline rs79639154 (GG/TG/TT) & 0 & 5.9 & 94.1 & 0 & 0 & 100.0 & 94.1 & 5.9 & 0 & 100.0 & 0 & 0 \\
\hline rs1359482195 (AA/CA/CC) & 0 & 5.9 & 94.1 & 0 & 11.1 & 88.1 & 94.1 & 0 & 5.9 & 88.1 & 0 & 11.1 \\
\hline rs1137101 (GG/AG/AA) & 29.4 & 52.9 & 17.6 & 27.8 & 50.0 & 22.2 & 17.6 & 0 & 82.4 & 22.2 & 0 & 77.8 \\
\hline rs1805094 (TT/GT/GG) & 0 & 23.5 & 76.5 & 0 & 22.2 & 77.8 & 76.5 & 0 & 23.5 & 22.2 & 0 & 77.8 \\
\hline rs13306520 (GG/AG/AA) & 0 & 5.9 & 94.1 & 0 & 5.6 & 94.4 & 94.1 & 0 & 5.9 & 77.8 & 0 & 22.2 \\
\hline rs13306522 (GG/AG/AA) & 0 & 0 & 100.0 & & 5.6 & 94.4 & 100.0 & 0 & 0 & 94.4 & 0 & 5.6 \\
\hline
\end{tabular}

Comment: $\mathrm{HOM}^{\mathrm{p}}$ - homozygous variant (biallelic single nucleotide substitution), $\mathrm{HET}$ - heterozygous variant (single allelic single nucleotide substitution), $\mathrm{HOM}^{\mathrm{N}}$ - homozygous variant (absence of nucleotide substitutions). 
find a significant effect of rs1137100 on the probability of development of obesity.

According to our data, heterozygous missense mutations rs1137100, rs1137101, rs1805094 are not accompanied by an increase in the risk of developing MUO during childhood.

According to the results of our study, the CT genotype rs 3790435 is more common in children with MUO (83.3\%) and less often in children with MHO (41.2\%).

It was found that a mutation located in the 5 '-UTR may be associated with the development of some features in the course of obesity. Thus, Juan Li et al. (43), having examined 205 patients with physiological body weight and 117 obese patients, found that the presence of TT/CT rs3790435 genotypes in obese individuals was accompanied by an increased risk of obstructive sleep apnea syndrome, compared with individuals with the CC genotype (44).

It should be emphasized that in the absence of a difference in the frequency of occurrence of various exon and intron SNPs of the LEPR gene in groups of children with MHO and with MUO, however, according to the results of multiple discriminant analysis, these groups significantly differed from each other in terms of the set of studied polymorphisms. According to ENCODE (ENCyclopedia Of DNA Elements), not only exome, but also intronic or intergenic SNPs can represent functional significant variants (45). Thus, we can assume that the presence of several heterozygous SNPs of the LEPR gene is a significant pathogenic factor that determines the risk of developing MUO in children.

In contrast to the described studies, for the first time we obtained data on the presence of an association of two copies of the LEPR rs3790435 gene with the presence of MUO traits. It is believed that CNVs affect gene expression and are involved in the formation of the phenotype (46, 47). Maria Pettersson et al. (48) demonstrated an increase in CNV up to $19 \%$ in obese patients. It also presents evidence of the effect of changing the CNV of one gene on the likelihood of developing obesity. In particular, it was shown that a decrease in the CNV of the AMY1 gene is associated with the development of overweight and low expression of IL-10 (49). In all likelihood, an increase in the CNV of the LEPR gene rs3790435 is associated with an increase in the activity of insulin resistance.

To determine the significance of LEPR gene polymorphisms in the development of MUO, it is necessary to further study their clinical associations in large cohorts of individuals with different obesity phenotypes.

\section{CONCLUSIONS}

Predictors of MUO formation in children are hyperleptinemia and male sex. The cumulative effect of the simultaneously present four or more SNPs of the LEPR gene predetermines the development of MUO. The greatest risk of MUO formation is associated with an increase in the CNV of the LEPR gene from rs3790435. The number of concurrently present different SNPs of the LEPR gene in one patient is associated with the level of the likelihood of MUO occurrence in childhood.

\section{AUTHORS' CONTRIBUTIONS}

AA was responsible for the idea and study design, looked over the articles, extracted the data, and interpreted bioinformatics analysis data. AN provided the collection of biological material using dried blood spot shipping kit, analyzed the data and interpreted it. Both authors reviewed the paper and approved the final manuscript.

\section{COMPLIANCE WITH ETHICAL STANDARDS}

Conflict of Interest: The authors declare that they have no conflict of interest.

Funding: The work is a fragment of the research work of the Department of Pediatrics 1 and Medical Genetics of the Dnipro State Medical University "Prediction of the development of childhood diseases associated with civilization" (state registration No 0120U101324). The study was carried out according to the budget program of the Code of program classification of expenses and crediting 2301020 "Scientific and scientific and technical activities in the field of health care", funded by the Ministry of Health of Ukraine from the state budget.

Ethical approval: All procedures performed in studies involving human participants were in accordance with the ethical standards of the institutional and/or national research committee and with the 2000 Helsinki declaration (52nd WMA General Assembly, Edinburgh, Scotland) and its later amendments or comparable ethical standards. The submissions were reviewed by the Ethics Committee of the Dnipro State Medical University (meeting minutes No. 7 of December 11, 2019 and minutes from meeting No. 5 of September 3, 2020).

Informed consent: Informed consent was obtained from all individual participants included in the study.

\section{REFERENCES}

1. Zhang Y, Chua S Jr. Leptin Function and Regulation. Compr Physiol 2017; 8(1): 351-69.

2. Izquierdo AG, Crujeiras AB, Casanueva FF, et al. Leptin, Obesity, and Leptin Resistance: Where Are We 25 Years Later? Nutrients 2019; 11(11): 2704.

3. Kleinendorst L, Abawi O, van der Kamp HJ, et al. Leptin receptor deficiency: a systematic literature review and prevalence estimation based on population genetics. Eur J Endocrinol 2020; 182(1): 47-56.

4. Thaker VV. Genetic and epigenetic causes of obesity. Adolesc Med State Art Rev 2017; 28(2): 379-405.

5. Kleinendorst L, Abawi O, van der Kamp HJ, et al. Leptin receptor deficiency: a systematic literature review and prevalence estimation based on population genetics. Eur J Endocrinol 2020; 182(1): $47-56$.

6. Nordang GBN, Busk OL, Tveten $\mathrm{K}$, et al. Next-generation sequencing of the monogenic obesity genes LEP, LEPR, MC4R, PCSK1 and POMC in a Norwegian cohort of patients with morbid obesity and normal weight controls. Molecular Genetics and Metabolism 2017; 1(121): 51-6.

7. Nunziata A, Funcke JB, Borck G, et al. Functional and Phenotypic Characteristics of Human Leptin Receptor Mutations. J Endocr Soc 2018; 3(1): 27-41.

8. Farooqi IS, Wangensteen T, Collins S, et al. Clinical and molecular genetic spectrum of congenital deficiency of the leptin receptor. N Engl J Med 2007; 356(3): 237-47.

9. Abaturov AE, Nikulina AA. (Phenotypes of obesity in children, clinical manifestations and genetic associations). Zdorov'e rebenka 2020; 4(15): 72-84. (In Ukrainian). 
10. Abaturov AE, Nikulina AA. Genotype C/C 13910 of the Lactase Gene as a Risk Factor for the Formation of Insulin-Resistant Obesity in Children. Acta Medica (Hradec Králové) 2019; 62(4): 150-5.

11. ACMG Board of Directors. Clinical utility of genetic and genomic services: a position statement of the American College of Medical Genetics and Genomics. Genetics in Medicine 2015; 17(6): 505-7.

12. Elkins C, Fruh Sh, Jones L, et al. Clinical Practice Recommendations for Pediatric Dyslipidemia. Journal of Pediatric Health Care 2019; 33(4): 494-504.

13. American Diabetes Association. 2. Classification and Diagnosis of Diabetes: Standards of Medical Care in Diabetes - 2019. Diabetes Care Jan 2019; 42(Suppl. 1): 13-28.

14. Alberti KG, Zimmet P, Shaw J. International Diabetes Federation: a consensus on Type 2 diabetes prevention. Diabet Med 2007; 24(5): 451-63.

15. Weihe P, Weihrauch-Blüher S. Metabolic Syndrome in Children and Adolescents: Diagnostic Criteria, Therapeutic Options and Perspectives. Curr Obes Rep 2019; 8(4): 472-9.

16. Ranasinghe $P$, Jayawardena $R$, Gamage N, et al. The range of non-traditional anthropometric parameters to define obesity and obesity-related disease in children: a systematic review. Eur J Clin Nutr 2021; 75: 373-84.

17. Lissner L, Lanfer A, Gwozdz W et al. Television habits in relation to overweight, diet and taste preferences in European children: the IDEFICS study. 2012; 27(9): 705-15.

18. Peplies J, Börnhorst C, Günther K, et al. IDEFICS consortium. Longitudinal associations of lifestyle factors and weight status with insulin resistance (HOMA-IR) in preadolescent children: the large prospective cohort study IDEFICS. Int J Behav Nutr Phys Act 2016; 13(1): 97.

19. McCarthy HD, Cole TJ, Fry T, et al. Body fat reference curves for children. Int J Obes (Lond) 2006; 30(4): 598-602.

20. Schwandt P, von Eckardstein A, Haas G-M. Percentiles of Percentage Body Fat in German Children and Adolescents: An International Comparison. Int J Prev Med 2012; 3(12): 846-52.

21. WHO child growth standards: length/height-for-age, weight-for-age, weight-for-length, weight-for-height and body mass index-for-age: methods and development. Geneva: WHO; 2006.

22. Hongshan J, Rong L, Shou-Wei D, et al. Skewer: a fast and accurate adapter trimmer for next-generation sequencing paired-end reads. In BMC Bioinformatics 2014; 15: 182.

23. Li H, Durbin R. Fast and accurate short read alignment with BurrowsWheeler transform. Bioinformatics 2009; 25(14): 1754-60.

24. Mose LE, Wilkerson MD, Hayes DN, et al. ABRA: improved coding indel detection via assembly-based realignment. Bioinformatics 2014; 30(19): 2813-5.

25. Wingett SW, Andrews S. FastQ Screen: A tool for multi-genome mapping and quality control. F1000Res 2018; 7: 1338.

26. Wickham H. ggplot2. Elegant graphics for data analysis. New York. 2016 Springer.

27. R Core Team: R: A Language and Environment for Statistical Computing. Vienna, Austria. 2015. (Accessed October 6, 2020, at https:// www.R-project.org/).

28. Rentzsch P, Witten D, Cooper GM, Shendure J, Kircher M. CADD: predicting the deleteriousness of variants throughout the human genome. Nucleic Acids Res 2019; 47(D1): D886-D894.

29. The CADD webserver (Accessed September 11, 2020, at https://cadd .gs.washington.edu/snv).
30. FILTUS (Accessed October 6, 2020, at https://github.com/magnusdv /filtus).

31. SeqVISTA (Accessed October 6, 2020, at http://zlab.bu.edu/Seq VISTA).

32. Mutationassessor.org functional impact of protein mutations release (Accessed October 6, 2020, at http://mutationassessor.org/r3/).

33. Volchikhin VI, Ivanov AI, Serikova YuI. Compensation of methodological errors in calculating standard deviations and correlation coefficients arising from the small volume of samples. Izvestiya VUZov. Volga region. Technical Science 2016; 1(37): 103-10. (In Russian).

34. Chung ST, Onuzuruike AU, Magge ShN. Cardiometabolic risk in obese children. Ann N Y Acad Sci 2018; 1411(1): 166-83.

35. Zimmet P, Alberti GM, Kaufman F, et al. The metabolic syndrome in children and adolescents: the IDF consensus. Diabetes Voice 2007; 52(4): 29-32.

36. Barstad LH, Júlíusson PB, Johnson LK, et al. Gender-related differences in cardiometabolic risk factors and lifestyle behaviors in treatment-seeking adolescents with severe obesity. BMC Pediatr 2018 ; $18(1): 61$.

37. Jamar G, Caranti DA, de Cassia Cesar H, et al. Leptin as a cardiovascular risk marker in metabolically healthy obese: Hyperleptinemia in metabolically healthy obese. Appetite 2017; 108: 477-82.

38. Fairbrother U, Kidd E, Malagamuwa T, Walley A. Genetics of Severe Obesity. Curr Diab Rep 2018; 18(10): 85.

39. Dos Santos Rocha A, de Cássia Ribeiro-Silva R, Nunes de Oliveira Costa $\mathrm{G}$, et al. Food Consumption as a Modifier of the Association between LEPR Gene Variants and Excess Body Weight in Children and Adolescents: A Study of the SCAALA Cohort. Nutrients 2018; 10(8): 1117.

40. Furusawa T, Naka I, Yamauchi T, et al. The Q223R polymorphism in LEPR is associated with obesity in Pacific Islanders. Hum Genet 2010; 127(3): 287-94.

41. Ali EMM, Diab T, Elsaid A, et al. Fat mass and obesity-associated (FTO) and leptin receptor (LEPR) gene polymorphisms in Egyptian obese subjects. Arch Physiol Biochem 2021; 127(1): 28-36.

42. Roszkowska-Gancarz M, Kurylowicz A, Polosak J, et al. Functional polymorphisms of the leptin and leptin receptor genes are associated with longevity and with the risk of myocardial infarction and of type 2 diabetes mellitus. Endokrynol Pol 2014; 65(1): 11-6.

43. Li J, Yang S, Jiao X, et al. Targeted Sequencing Analysis of the Leptin Receptor Gene Identifies Variants Associated with Obstructive Sleep Apnoea in Chinese Han Population. Lung 2019; 197(5): 577-84.

44. Li J, Yang S, Jiao X, et al. Targeted Sequencing Analysis of the Leptin Receptor Gene Identifies Variants Associated with Obstructive Sleep Apnoea in Chinese Han Population. Lung 2019; 197(5): 577-84.

45. ENCODE Project Consortium. An integrated encyclopedia of DNA elements in the human genome. Nature 2012; 489(7414): 57-74

46. Almal SH, Padh H. Implications of gene copy-number variation in health and diseases. J Hum Genet 2012; 57(1): 6-13.

47. Lauer S, Gresham D. An evolving view of copy number variants. Curr Genet 2019; 65(6): 1287-95.

48. Pettersson M, Viljakainen H, Loid P, et al. Copy Number Variants Are Enriched in Individuals With Early-Onset Obesity and Highlight Novel Pathogenic Pathways. J Clin Endocrinol Metab 2017; 102(8): 3029-39.

49. Selvaraju V, Venkatapoorna CMK, Babu JR, Geetha T. Salivary Amylase Gene Copy Number Is Associated with the Obesity and Inflammatory Markers in Children. Diabetes Metab Syndr Obes 2020; 13: 1695-701. 